\section{artelogie}

\section{Artelogie}

Recherche sur les arts, le patrimoine et la littérature de l'Amérique latine

10 | 2017

Après le paysage : l'art, l'inscription et la représentation de la nature en Amérique latine aujourd'hui

\title{
Viagem pitoresca e histórica ao Brasil, de Jean-Baptiste Debret, Jacques Leenhardt (prefacio)
}

\section{Raphael Fonseca}

\section{OpenEdition}

\section{Journals}

Edição electrónica

URL: http://journals.openedition.org/artelogie/877

DOI: $10.4000 /$ artelogie. 877

ISSN: 2115-6395

Editora

Association ESCAL

Refêrencia eletrónica

Raphael Fonseca, «Viagem pitoresca e histórica ao Brasil, de Jean-Baptiste Debret, Jacques Leenhardt (prefacio) », Artelogie [Online], 10 | 2017, posto online no dia 05 abril 2017, consultado o 23 setembro 2020. URL : http://journals.openedition.org/artelogie/877 ; DOI : https://doi.org/10.4000/artelogie.877

Este documento foi criado de forma automática no dia 23 setembro 2020.

Association ESCAL 


\title{
Viagem pitoresca e histórica ao Brasil, de Jean-Baptiste Debret, Jacques Leenhardt (prefacio)
}

\author{
Raphael Fonseca
}

\section{REFERÊNCIA}

Jean-Baptiste Debret, Jacques Leenhardt (prefacio), Viagem pitoresca e histórica ao Brasil, São Paulo, Imprensa Oficial do Estado de São Paulo, 2016, 652p.

O presente ano de 2016 é um momento de comemorações e lembrança dentro do campo dos estudos da arte e da imagem durante o século XIX no Brasil. Trata-se da celebração dos duzentos anos da vinda de um grupo de artistas franceses para o Rio de Janeiro, em 1816, então capital do Império Luso-Brasileiro. Essa viagem foi posteriormente batizada de "Missão artística francesa" e se trata da soma de dois desejos: a saída do território francês de artistas um dia associados politicamente a um Napoleão em iminente queda política e, por outro lado, o desejo por parte do imperador português D. João VI de haver uma escola de belas-artes em território brasileiro. Portugal, importante lembrar, sequer havia uma instituição dessa espécie na Europa e, portanto, a presença destes artistas no Brasil poderia colaborar com o desenvolvimento de uma cultura visual embebida na tradição clássica europeia (e nas iconografias imperiais) em plenos trópicos.

2 Nesse desejo de revisão desse bicentenário eventos e publicações tem sido organizados em torno destes artistas que vieram ao Brasil e de suas consequências para o ensino das artes visuais no país. Um deles se trata da mais recente reedição da clássica publicação "Viagem pitoresca e histórica ao Brasil", de autoria do artista francês Jean-Baptiste Debret (1768-1848), lançada em 2015 pela editora Imprensa Oficial do Estado de São Paulo. O livro tem recebido atenção da mídia especializada e foi objeto de um evento organizado na Casa de Rui Barbosa, no Rio de Janeiro, intitulado "200 anos da 
descoberta do Brasil por Jean-Baptiste Debret". Organizado pelo professor Jacques Leenhardt, diretor da Escola de Altos Estudos em Ciências Sociais de Paris, o livro se configura como a terceira edição em português dos textos escritos por Debret e relativos à sua estadia no Brasil.

Nascido em Paris, em 1768, e falecido na mesma cidade, em 1848, Debret foi aluno da Escola de Belas-Artes e possuía forte formação neoclássica. Primo de Jacques-Louis David, era especialista na pintura de gênero histórico e recebeu o prêmio de viagem para Roma em 1791. Desde 1816, logo ao chegar no Brasil, entre encomendas de retratos e de pinturas históricas para D. João VI e seu filho, D. Pedro I, Debret constrói cenas da cidade do Rio de Janeiro. $O$ artista realiza uma extensa série de imagens em que se debruça sobre a rotina da capital. As relações de poder, o trabalho, a essencial presença dos africanos escravizados e as comunidades indígenas são alguns dos grandes grupos de imagens que realiza. Com pequenos formatos que não ultrapassavam os trinta centímetros de largura, Debret se utiliza do desenho e das técnicas de aquarela a fim de conseguir recodificar em pequenas narrativas o dia a dia desta parte dos trópicos.

4 Enquanto isso, ele e outros artistas franceses que se transladaram para o Brasil em sua companhia, como Grandjean de Montigny, Nicolas-Antoine Taunay e Joachin Lebreton, amadureceram o projeto de criação de uma Escola Real de Ciências, Artes e ofícios, futura Academia Imperial de Belas-Artes. Se o prédio da mesma foi erguido em 1822, a sua inauguração só se deu em 1826, dez anos após a chegada do grupo. A partir desse ano, por fim, Debret era o responsável pela cadeira de pintura histórica, sendo também o diretor da instituição entre 1828 e 1831, quando retorna à Europa.

5 Em 1834, na França, reúne cento e cinquenta e três de suas aquarelas e as transforma em litografias, sendo ele mesmo o responsável pela operação dessa técnica. Esta seleção se converte no seu álbum que dissemina pela Europa imagens de um Brasil em pleno processo de expansão e adequação à presença da corte portuguesa somado a um imaginário que enxergava esse território como selvagem e virgem. Debret também se responsabilizou pela análise textual da sociedade brasileira. Tratava-se não de uma viagem qualquer, mas de um deslocamento que, ao ser narrado por suas próprias palavras, ganha tons pitorescos e históricos: mantem-se o tom de contraste entre Europa e América, frisando as peculiaridades locais que eram dignas de "serem pintadas", mas sempre com um compromisso histórico onde a jovem História do Brasil era comentada através de documentos e o olhar crítico de Debret era exercido.

Dividido em três volumes, o livro tem uma linearidade discursiva muito clara. o primeiro deles diz respeito às observações do autor quanto aos grupos indígenas que supostamente observou durante sua estadia brasileira e "documentou" através de imagens. Distintos grupos indígenas se convertem em imagem e texto, havendo também capítulos dedicados exclusivamente aos seus diferentes objetos (como cestos, cerâmicas e armas), além, ao fim do volume, de um mapa do Brasil. O segundo volume apresenta um olhar mais detido sobre a rotina e costumes dos espaços mais metropolitanos do Brasil, próximos à vivência de Debret e centrados, em sua maior parte, no Rio de Janeiro. Temos, então, um contraste entre os dois primeiros volumes: de um lado, o indígena visto no que restava de seu ambiente "natural", em uma chave de leitura primitivista, mas também atenta aos indígenas "aculturados"; do outro, descrições do cotidiano da capital do império, onde havia um denso compartilhamento diário do espaço entre negros escravizados, imigrantes europeus e proprietários de estabelecimentos comerciais. Já o terceiro volume de sua obra se concentra em rituais 
religiosos (casamentos, enterros e festas públicas), além de descrições de vestuários e cortejos militares.

7 Se em 1816, Debret chega, coincidentemente, na semana de falecimento da rainha de Portugal, D. Maria I, e trabalha já na coroação de D. João VI, em 1831, ao partir do Brasil, vê um império independente do governo português, com D. Pedro I na liderança e prestes a também retornar a Portugal, abdicando de seu trono para seu filho, D. Pedro II. Nesses quinze anos, portanto, a política brasileira nasce perante Debret e seu olhar ávido pelo processo civilizatório. O que Debret tenta organizar em seu livro, portanto, é um processo de "ocidentalização" do Brasil. Como qualquer tentativa de fazê-lo, era impossível não frisar e demonstrar através de imagens aqueles pontos fora da curva do que seria uma sociedade civilizada segundo a sua experiência na França. Como enxergar aspectos civilizatórios em um território ainda repleto de indígenas e onde a escravidão era uma das colunas do desenvolvimento do país?

8 A nova publicação em português do livro de Debret é importante de modo imediato devido à distância de suas outras edições: a primeira foi feita por Sérgio Milliet na década de 1940 e a segunda editada no final dos anos 1980. Em outras palavras, há mais de vinte anos se aguardava por uma edição mais acessível às palavras de Debret no mercado editorial brasileiro. Qualquer pesquisador do assunto sabe bem da dificuldade de encontrar ou comprar essas edições anteriores do texto e esse novo livro certamente cumpre esse papel.

O texto que foi base para a publicação foi justamente a primeira tradução feita para o português de Milliet. Atualizações na escrita portuguesa foram feitas devido à distância de setenta anos entre as duas publicações. O organizador Jacques Leenhardt - também responsável pela primeira reedição em francês da obra - optou por contribuir não só com a edição do texto, mas também com um importante artigo a respeito da produção e percurso de Debret. Intitulado "Um olhar transversal sobre a construção da nação brasileira", o autor analisa as alterações formais e de abordagem perante o cotidiano que as obras de Debret sofreram da sua passagem da França para o Brasil.

De todo modo, como não poderia deixar de ser em qualquer publicação impressa, há elementos que colocam o pesquisador em dúvida. Em primeiro lugar, é importante realçar a opção editorial de inserir no mesmo livro os três tomos de Debret. Em vez, então, do leitor enxergar separadamente as três obras de Debret (que foram publicadas, respectivamente, em 1834, 1835 e 1839), ele tem em suas mãos as três partes agrupadas num todo. Isso poderia até ser interessante, mas a opção de produzir o livro em tamanho A4 faz com que as seiscentas e cinquenta e duas páginas da publicação cheguem a quase quatro quilos e o próprio ato de carregar e folhear o livro se tornem algo cansativo.

11 Essas opções quanto ao formato de impressão levam a outro fator delicado dentro do mercado editorial brasileiro e da realidade socioeconômica do país: o livro tem um valor alto e, ao menos no website da editora, ultrapassa a faixa dos duzentos reais. Poder-se-ia argumentar que o público-alvo do texto é aquele especializado na área das artes visuais (e que supostamente teria o capital necessário para adquiri-lo), porém, entrar automaticamente nessa linha de pensamento não contribui com uma maior disseminação e popularização da importante escrita de Debret. 0 valor que a publicação possuía devido à sua disponibilização atualizada do texto aqui comentada, agora tem como obstáculo um custo que, certamente, não será proporcional ao bolso 
especialmente de considerável parcela jovens pesquisadores, acadêmicos e leitores leigos que possam se interessar pelas palavras do francês.

Por fim, entrando nos campos da diagramação e do design, o organizador e a editora optaram por utilizar as gravuras aquareladas de Debret para estabelecer a relação imagem-texto com suas palavras. A opção é interessante e difere das edições anteriores do livro, mas também levanta a dúvida sobre até que ponto não seria mais interessante utilizar uma edição preto-e-branca, algo mais próximo do que circulava em maior volume na Europa quando foi lançado. 0 tamanho grande das imagens faz também com que o texto tenha um prosseguimento sem interrupções, ou seja, por vezes segmentos que eram separados na versão original para estabelecerem relações com as imagens, aqui são agrupados na mesma página. Isso faz com que as imagens não venham associadas diretamente ao texto e levam o leitor a folhear a publicação em busca do seu par de texto ou imagem.

Essas observações sobre o livro de nenhum modo retiram sua importância para o estado atual das publicações no Brasil de fontes primárias tanto para os estudos sociológicos, quanto para os estudos histórico-artísticos. Mesmo que seja trabalhado e citado por diversos pesquisadores das relações entre arte, imagem e identidade no Brasil, as abordagens em torno da obra de Jean-Baptiste Debret tendem a ser exclusivamente sobre sua produção imagética e costumam fazer vista grossa à sua imprescindível relação entre seu olhar plástico sobre o outro e seus comentários textuais a respeito do mesmo. Talvez esses pequenos ajustes quanto à forma do livro trariam ao público interessado um resultado mais fidedigno às primeiras versões do livro em francês. Esse dado, somado a uma readequação de seu formato e valor do livro, seriam capazes de ampliar seu alcance e qualidade enquanto livro.

Uma versão digital do mesmo - algo ainda inexistente - certamente seria uma maneira mais barata e acessível de se comprar uma publicação que ainda fica restrita a um número específico de cópias impressas. Além disso, o formato digital também convida a uma maneira de pesquisa mais transversal e que faz com que as palavras de Debret possam ser acessadas tanto a partir de um interesse voltado para o seu todo, quanto para leitores que desejam buscar um tema específico dentro de seu livro monumental.

Fica a certeza de que, felizmente, as imagens e frases de Debret, duzentos anos depois de sua presença no Brasil, seguem importantes, potentes e convidativas para novas abordagens, cruzamentos e estudos.

\section{AUTORES}

\section{RAPHAEL FONSECA}

Doutor em História da arte, Universidade Federal de Rio de Janeiro.

raphaelfonseca[at]gmail.com 